\title{
Study on Integrated Planning and Management in Lhasa River Basin
}

\author{
SU Huidong ${ }^{1}$, LIU Yin ${ }^{1}$, LU Huiting ${ }^{2}$, Wang Dongbo ${ }^{3}$, JIN Tianian ${ }^{1 *}$ \\ ${ }^{1}$ The State Key Laboratory of Simulations and Regulations of Water Cycles in River Basins (SKL-WAC), China Institute of Water \\ Resources and Hydropower Research (IWHR), Beijing 100038, China \\ ${ }^{2}$ State Key Laboratory of Urban and Regional Ecology, Research Center for Eco-Environmental Sciences, Chinese Academy of Sciences, \\ Beijing 100085, China \\ ${ }^{3}$ Environmental Monitoring Center of Inner Mongolia, Hulunbeir 021008, China
}

\begin{abstract}
As a political, economic and cultural center of the Tibet Autonomous Region, the Lhasa River needs to take planning and management of the basin. In the past 60 years, the temperature of Lhasa River Basin has been increasing gradually at an annual rate of $0.047^{\circ} \mathrm{C}$, which leads to the water cycle variation of the river basin and its associated aquatic ecology and environment continue to change and evolve, and ecological environmental protection is affected by more uncertain factors. Based on the assessment of the ecological environment of the Lhasa River Basin, the comprehensive planning suggestions for the Lhasa River Basin were proposed from the aspects of water environment, land use, ecological pattern, and economic and social development. These suggestions are drawn on the examples of integrated planning and management of catchment in foreign countries and are referred to as the comprehensive planning of the seven major river basins in China.
\end{abstract}

\section{Introduction}

The issues such as water resources management, water environment restoration, and water ecology protection have increasingly become key issues that restricting China's economic and social development [1]. To achieve the harmonious coexistence between human and water, the goals of the four major systems of flood control and disaster reduction in the river basin, comprehensive utilization of water resources, environmental protection of water resources and aquatic ecology, and integrated river basin management need to be improved under the relevant legal guarantees of the Water Law task [2]. At present, the seven major river basins of China have carried out comprehensive river basin planning on behalf of their characteristics, and all planning were approved by the State Council of China [3]. i.e., Yangtze River [4], Yellow River [5], Huai River, Haihe River [6], Pearl River [7], Songhua River [8], Liaohe River [9], and Taihu Lake [10]. However, with the rapid development of economy and society of China plus the uncertain impact of climate change, new changes in the aquatic environment of the river basin have become more complicated, and the previous plans have failed to meet the future sustainable development needs of the river basin.

Lakes on the Tibetan Plateau are sensitive indicators of global climate change [11, 12]. In the past 60 years, the temperature of the Lhasa River Basin has been increasing gradually at an annual rate of $0.047^{\circ} \mathrm{C}$. Driven by global climate change[13] and increasingly strong human activities[14], the water cycle of the river basin and its associated aquatic ecology and water environment process continue to evolve, and ecological environmental protection is affected by more uncertain factors. On the one hand, to adapt to the needs of sustainable development of river basins in a changing environment, China's integrated planning and management of basin needs to keep pace with the times and adjust continuously from the past engineering water conservancy to resource water conservancy, ecological water conservancy and intelligent water conservancy. On the other hand, it is necessary to follow the principle of adapting to local conditions and fully consider the local natural resource endowment, industrial structure layout, water supply pattern, etc.

The Lhasa River Basin is located in the central and southern part of the Tibet Plateau and is the political, economic, cultural center and transportation hub of the Tibet Autonomous Region. In the past 50 years, the construction of Lhasa's industry, agriculture, and urban have made great progress, especially the "one river plus two rivers" comprehensive development project that began in the early 1990s, which has greatly promoted the region's agriculture, water and other aspects of construction [15]. Since then, the Lhasa River has provided water guarantees in various aspects for the region and ensured rapid economic and social development in the region. However, the development of economic society has gradually strengthened the interference of human activities on natural ecosystems, and the ecological environment has been exacerbated by external risks of climate change. In addition, the Lhasa

${ }^{*}$ Corresponding author: JIN Tiantian (jtt_05@163.com) 
River Basin Plan needs to focus on the characteristics of the basin's high altitude, ecological fragility, economic development, and lagging information sharing [16]. Therefore, coordinating the development and utilization of water resources and ecological environment protection, and ensuring the sustainable development of economy and society, is an urgent problem to be solved. Based on the assessment of the ecological environment of the Lhasa River Basin, the comprehensive planning suggestions for the Lhasa River Basin were proposed from the aspects of water environment, land use, ecological pattern, and economic and social development. These suggestions draw on the examples of integrated planning and management of basin in foreign countries and refer to the comprehensive planning of seven major river basins in China.

\section{Study Area}

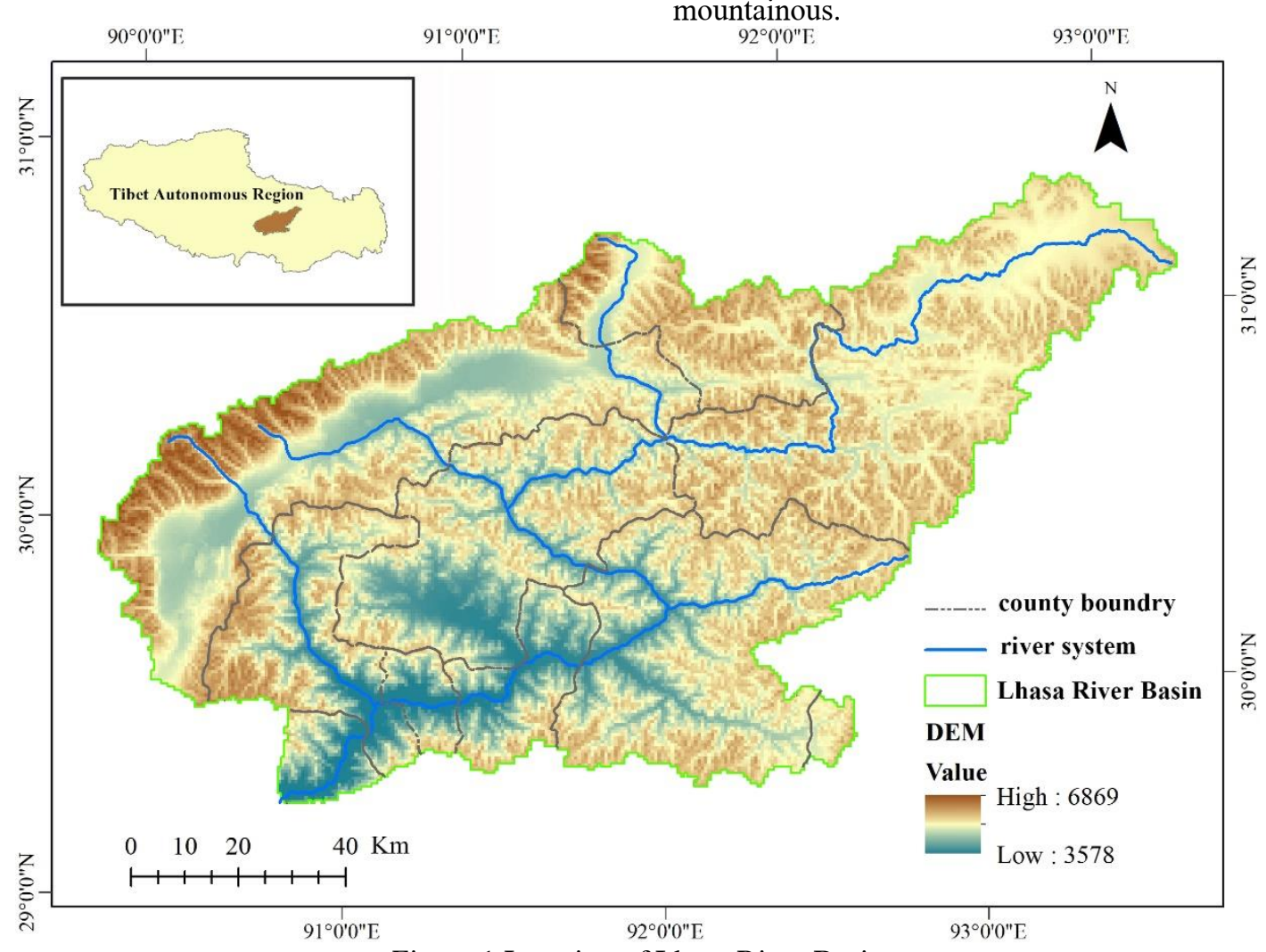

Figure 1 Location of Lhasa River Basin

\section{Assessment of ecological environment in the Lhasa River Basin}

Based on the characteristics of the ecological environment of the Lhasa River Basin, this paper evaluates the current status of the ecological environment of the basin from four main aspects, including water quality, aquatic organisms, ecosystem service functions, socio-economic development.

\subsection{Water quality}

Lhasa River basin $\left(29^{\circ} 20^{\prime} \sim 31^{\circ} 15^{\prime} \mathrm{N}, 90^{\circ} 05^{\prime} \sim 93^{\circ} 20^{\prime} \mathrm{E}\right)$ is located on the Tibet Plateau and is the political, economic and cultural center of the Tibet Autonomous Region (Figure 1). The elevation of the birthplace of the river is about $5550 \mathrm{~m}$, and the elevation of the outlet is about 3575 $\mathrm{m}$. The Length of the main channel is $551 \mathrm{~km}$, and the river ratio drops by $0.29 \%$. The multi-year average annual runoff is $1.10 \times 1010 \mathrm{~m}^{3}$. The total area of the basin is $32488 \mathrm{~km}^{2}$. Most of the runoff recharge comes from precipitation, and a small part comes from groundwater recharge and glacial meltwater recharge. The average annual temperature in this area is $-1.02 \sim 8.81{ }^{\circ} \mathrm{C}$, and the average annual precipitation is $392 \sim 677 \mathrm{~mm}$. The annual precipitation distribution is extremely uneven, mainly concentrated in June to October, accounting for about $90 \%$ of the annual precipitation. The terrain is low in the south and high in the north, with an average elevation of about $4,500 \mathrm{~m}$. The geomorphology of the study area belongs to the wide valley of the southern Tibet, and most areas are mountainous.

On the scale of the Lhasa River Basin, the water quality of the Lhasa River is good. There have been no significant pollution incidents in the past 20 years (1995-2014). Except for the 2012 Total Phosphorus pollution index, the rest of the projects are in line with Class II quality Claim. The $\mathrm{pH}$ value has increased in recent years, more than 8.2 , and the highest value is 8.5 . The chemical oxygen demand (COD) and total phosphorus (TP) pollution indexes have increased significantly in recent years, and water bodies may be contaminated with organic or reducing substances. The concentrations of five heavy metals, including $\mathrm{Cu}, \mathrm{As}$, $\mathrm{Hg}, \mathrm{Cr}^{6+}$, and $\mathrm{Pb}$ have not exceeded the limits set by the national surface water Class II environmental quality standards for many years. The risk of water and metal contamination is small [17]. In recent years, the pollution 
indexes of $\mathrm{pH}, \mathrm{DO}, \mathrm{NH}^{3}-\mathrm{N}$ and $\mathrm{TP}$ in a water body are relatively high, which are the main pollution indexes of water environment in Lhasa River Basin at present, and also need to be focused on and controlled in the future.

From a long-time scale, the water environment of the Lhasa River Basin is generally in a good state. However, due to human activities and the impact of climate change, the water environment of the Lhasa River has declined, but the trend is not significant. The key driving factors of environmental change include the influence of precipitation, livestock stocks, population, rural population, and national economic production. Among them, rural agricultural non-point source pollution is the main source of pollution in the Lhasa River Basin, and we must focus on and control it.

\subsection{Aquatic organisms}

The water ecology of the Lhasa River is relatively fragile, and the diversity index is low due to the small number and type of organisms [18]. The Lhasa River is rich in phytoplankton and phytoplankton, most of which are characterized by their ability to withstand cold and high light [19]. Beginning in the 1990s, overfishing and alien species invasion have brought great challenges to fish protection. Several of the 15 species of native fish are endangered, and most of them have fallen sharply. However, considering the ecological fragility of highprototype rivers, its recovery is more difficult, so it should be prevented beforehand, and protection should be strengthened [20].

\subsection{Ecosystem service functions}

From 1990 to 2015, the spatial pattern of soil conservation capacity, carbon sequestration capacity, habitat quality, and water conservation capacity in the Lhasa River Basin remained almost unchanged, with little change in the total amount [21]. Generally speaking, the ecological environment of the Lhasa River Basin is in a relatively safe state. The area of unsafe and less safe areas accounts for about $28 \%$ of the basin area. The focus of attention in the basin is the source and upstream area (northern area). The area of highly sensitive area accounts for about $3 \%$ of the basin area, and the sensitivity of soil erosion is generally low. The comprehensive ecological sensitivity of the basin is mainly distributed in the middle and north of the basin and the Tanggula Mountain in Nianqing. The high-risk areas of landslide and debris flow are mainly distributed in the river valley areas in the south of the basin, such as Mozhugongka County, Dazi county and the southwest of Linzhou county. The risk area of habitat degradation is very small, and it is mainly distributed in the area with a high intensity of human activities in the mainstream of Lhasa River.

\subsection{Socio-economic development}

3.4.1 Land use changes According to the statistics of the average NDVI (provided by Institute of Remote Sensing and Digital Earth, Chinese Academy of Sciences) in the growing season (from June to October), in general, NDVI of various types of vegetation increased significantly from 1990 to 2000, but meadows and grasslands have shown a significant trend of degradation since 2000. From 2000 to 2010, the area of wetland and artificial surface (urban construction land) increased significantly. The sources of the increase were mainly grassland and cultivated land. In contrast, grassland area has decreased dramatically. From 1990 to 2015, the artificial surface area continued to increase. The artificial surfaces in Lhasa, Daz County, Mozhu Gongka County, Duilong Deqing County, Dangxiong County, and Linzhou County all changed strongly, and the urbanization process continued to intensify.

3.4.2 Socio-economic development In recent years, Lhasa's economy and population have grown rapidly. As of the end of 2014, the total population of Lhasa was about 530,000 , of which the male-to-female ratio was 49.6: 50.4, the urban-rural ratio was $42.3: 57.7$, and the population growth rate was $8.1 \%$. As of the end of 2014, Lhasa's GDP reached 34.745 billion yuan, and the GDP growth rate has been greater than $10 \%$ since 2002 . The industrial structure of the three industries was adjusted from 24.6: 22.0: 52.4 in 1978 to 3.7: $36.8: 59.5$ in 2014 (Figure 2). The growth rate of the tertiary industry was significantly greater than that of the primary and secondary industries, and the proportion was the highest. The transformation of the economic structure with the primary industry as the main body and the secondary industry and the tertiary industry focusing on development has been realized. 


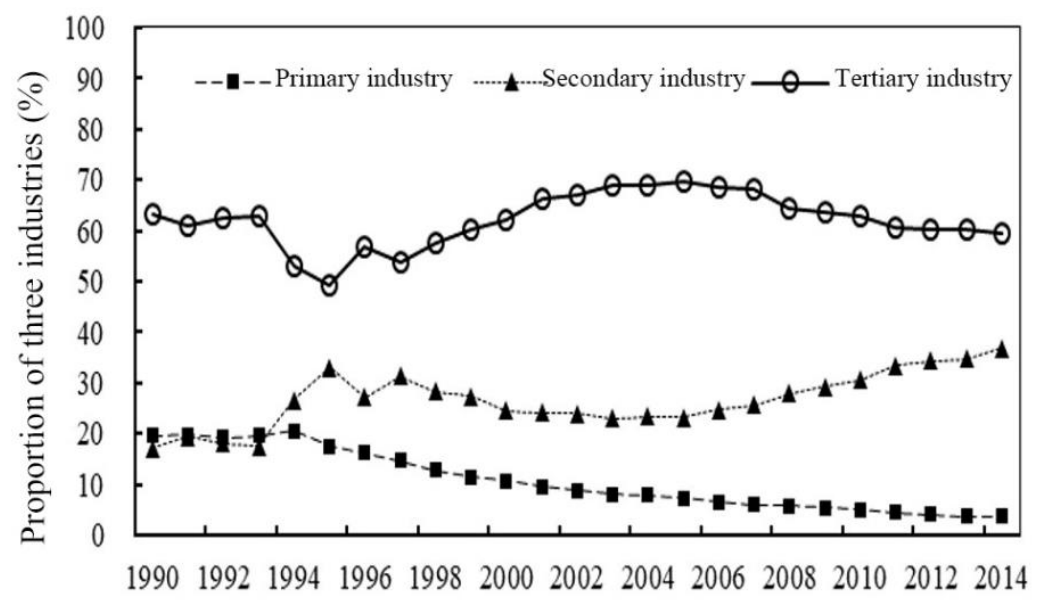

Figure 2 Proportion of three industries in Lhasa River Basin form 1990 to 2014

\section{Recommendations for integrated planning and management of Basin}

\subsection{Strengthen the construction of laws}

Comprehensive river basin planning and management is not only an engineering technology for river basin management but also a law for river basin management [22]. However, the current system of integrated management of river basin ecological environment is still not perfect. The legal basis of the river basin management is scattered in water-related laws or related regulations on resources and the environment [23], and there are a lack of a complete, systematic and basic river basin management basic legal system and basic law of implementation mechanism. Implement the "river chief system" management and integrate the funds of all stakeholders to support the government's water resource planning and management. For the harmonious economic and social development of the whole basin and even the country, we need to take into account the flood control security, water supply security, food security and ecological security of the basin.

\subsection{Increase hydropower development properly}

The Lhasa River Basin is rich in water resources, and the current utilization rate is still relatively low [24]. The construction of water conservancy projects, on the one hand, can play a role in generating electricity, preventing floods, and ensuring the safety of water resources, which is beneficial to the development of the economy and people's livelihood. On the other hand, the Lhasa River has a larger descent and greater water energy, which is not conducive to biodiversity and stability. Appropriate hydropower development can reduce potential energy and improve river hydrodynamic conditions, but it is conducive to maintaining ecological diversity and stability. In general, the advantages of constructing hydropower stations in the Lhasa River Basin outweigh the disadvantages, and the development of water conservancy projects can be properly and reasonably planned.

\subsection{Build a data monitoring and sharing platform}

Data monitoring is a basic means of adjusting planning. Due to the comprehensive influence of economic conditions, geographical location, extreme climate and environment, and human and material resources, various monitoring data in the Lhasa River Basin are relatively scarce. Therefore, more monitoring stations and platforms for information collection, transmission and management need to be established. Realize the monitoring platform's automation, full coverage, and safety and reliability. And gradually transform them into a smart station network or even a smart station network. In addition, more advanced portable equipment or instruments are introduced to replace cumbersome and old monitoring facilities, and appropriate methods such as satellite remote sensing, GPS, and GIS are used to collect soil, vegetation, water quality, flow, hydrology, meteorology, and biological information. Establish a data-sharing network to promote the development of ecological security research in the Lhasa River Basin, and allow more scholars to participate in planning and suggestions. Combine data with the model, introduce WEP [25], Mike [26], SWAT, etc. to carry out model application, so as to improve the resonance of comprehensive planning and management.

\subsection{Protect the ecology of the Lhasa River}

Affected by alien fish species, the invasion of alien species has become the biggest threat to local fish species in the Lhasa River, and some native fish species are endangered. Due to their ecological fragility, restoration efforts are extremely difficult. Besides, human fishing has become another major challenge for the survival and reproduction of local fish in the Lhasa River, which needs to be paid enough attention by the government and local people. Therefore, on the one hand, fisheries are banned in a critical ecological period on the Lhasa River, artificial fisheries are encouraged, and the problem of overfishing of fish on the Lhasa River is encouraged. Strengthen public awareness of local fish protection and improve river management. What's more, the collection of fish data needs to be strengthened, and a unified and 
comprehensive fish resource database needs to be constructed.

\section{5 mange water environment}

4.5.1 Restore water quality The water quality of the Lhasa River is significantly better than the major rivers in China such as the Yangtze River and the Yellow River, but it also faces great challenges. For example, the water quality of the Lhasa River is mainly affected by special natural hydrogeological conditions such as geothermal wastewater and high altitude, such as heavy metals arsenic. In addition, wastewater discharge in irrigation and livestock areas and non-point source pollution in rural areas should. As for urban industrial and domestic sewage, attention should be paid to saving water, reducing sewage discharge, and increasing the utilization of water resources. We will plan for comprehensive river basin improvement and implement the "river chief system" management.

4.5.2 Protect aquatic environment In comprehensive planning and management of the wetlands, riparian zones and habitats of the Lhasa River, engineering construction and management regulation must be combined together. The former is the foundation. Without engineering infrastructure, management and regulation will be difficult to achieve. The latter is a means. Although there is an engineering foundation but there are no strong management and regulation measures, engineering construction will not be effective.

\section{Conclusion}

This paper analyses and evaluates the water environment, land use, ecological pattern, and economic and social development of the Lhasa River Basin, and proposes comprehensive planning recommendations for the Lhasa River Basin. The specific conclusions are as follows: In general, the water environment of the Lhasa River Basin is in a good state, and all other years except 2012 have met the surface water category II water quality standards. Due to human activities and the impact of climate change, the water environment of the Lhasa River has declined, but the trend is not significant. From 1990 to 2015, the spatial pattern of soil conservation capacity, carbon sequestration capacity, habitat quality, and water conservation capacity in the Lhasa River Basin remained almost unchanged, and the total amount changed only a little. Besides, we put forward the following suggestions: first of all, strengthen the construction of river basin laws and regulations, and implement the "river chief system" management. Secondly, it is suggested to reasonably plan the development of water conservancy projects. Thirdly, more monitoring station networks and information collection, transmission and management platforms should be established to realize the monitoring and sharing of river basin data. Fourth, in the face of the sharp decline of local fish in Lhasa River, it is suggested to implement a comprehensive ban on fishing in the critical period, encourage the cultivation of artificial fisheries, and do a good job in the prevention of alien species invasion. Finally, in view of water environment treatment, rural areas need to focus on non-point source prevention and control, urban areas should focus on water conservation and emission reduction, and strengthen the construction of sponge cities.

\section{Acknowledgements}

The authors gratefully acknowledge the financial supports from National key R \& D plan of China under No. 2016YFC0502103-02 and supports from key science and technology plan project of Tibet Autonomous Region (Z2016C01G01/08)

\section{Reference}

1. Zhang Xiangpeng. Study on the legal system of integrated river basin management in China [D]. China University of Geosciences (Beijing), 2009.

2. Chen Yiyu. Research on integrated management strategies of Chinese river basins [M]. Science Press, 2007.

3. Comprehensive planning of seven river basins in China has been approved by the State Council [J]. Construction machinery, 2013 (06): 16

4. Wang Xincai. Review and Prospect of water conservancy planning in the Yangtze River Basin [J]. People's Yangtze River, 2008, 39 (20): 1-4

5. Xue Songgui. Summary of comprehensive planning of water resources in the Yellow River Basin [J]. Sinohydro, 2011 (23): 108-111.

6. Hu Zuoliang. Grasping the Comprehensive Planning Strategy of the Basin and Actively Promoting the Construction of the Water Conservancy System--An Interpretation of the Comprehensive Planning of the Haihe River Basin [J]. China Water Resources, 2013 (13): 45-47.

7. Zhu Yuxi, Zhang Hongwei. Discussion on Comprehensive Improvement and Restoration Planning of Qianshan River Basin in Zhuhai [J]. China Water \& Wastewater, 2017 (16).

8. Han Junshan. Implementation of the Comprehensive Planning of the Songhua River Basin Provides Water Conservation for Strategic Objective of Revitalizing Northeast China [J]. Northeast Water Resources \& Hydropower, 2013, 31 (7): 8-10.

9. $\mathrm{Wu}$ Jie, Chen Juan, Ni Wei. Summary of Comprehensive Planning of Liaohe River Basin " [J]. Journal of Northeast Water Resources and Hydropower, 2013, 31 (7): 18-20.

10. Ye Shouren, Zhu Wei. Summary of Integrated Water Resources Planning in the Taihu Basin [J]. China Water Resources, 2011 (23): 118-120.

11. Ding Yongjian, Liu Shiyin, Ye Baisheng, et al. Analysis of climatic factors of lake changes in cold and arid regions of China in recent 50 years $[\mathrm{J}]$. JOURNAL OF GLACIOLOGY AND GEOCRYOLOGY, 2006, 28 (5): 623-632.

12. Lu Anxin, Wang Lihong, Yao Tandong. Research on Remote Sensing Methods for Modern Changes of 
Lakes on the Tibetan Plateau [J]. Remote Sensing Technology and Application, 2006, 21 (3): 173-177.

13. HAO Xingming, CHEN Yaning, LI Weihong. Analysis of Driving Forces of Ecological Environment Changes in the Tarim River Basin in the Past 50 Years [J]. Acta Geographica Sinica, 2006, 61 (3): 262-272.

14. Wang Ranghui, Fan Zili. Evaluation of Ecological Vulnerability of Inland River Basins in Arid Areas_- Taking Xinjiang Tarim River Basin as an Example [J]. Chinese Journal of Ecology, 2001, 20 (3): $63-68$.

15. Xi Xuedong, Zhang Yanli, Yao Zhijun, et al. Analysis of runoff trends in the Lhasa River Basin in the past 50 years [J]. Progress in Geographical Sciences, 2007, 26 (3): 58-67.

16. Xu Hailiang, Fan Zili, Yang Pengnian, et al. Evaluation of the recent control of the Tarim River and suggestions for the preparation of comprehensive river basin planning [J]. Arid Land Geography, 2015, 38 (4): 645-651.

17. Zhang H. F., Liu H, Su H. D., Jin T. T., Lin B. B., Lin $\mathrm{J}$ Q. Analysis on trend and driving force for water environmental change of the Lhasa River basin (1995-2014). Acta Ecologica Sinica, 2019, 39(3): 770-778.

18. Jun Shan, Wang Dongbo, Zhou Jianhua, et al. Community structures of phytoplankton and its relationship with environmental factors in the Lhasa River. Acta Ecologica Sinica, 2019, 39 (3): 787 798

19. Lv Yonglei, Hao Shixin, Wang Chong, et al. Survey and analysis of plankton and fish resources in the source waters of the Lhasa River $[\mathrm{J}]$. Ocean and Lake Marsh, 2016, 47 (2): 407-413.

20. Chen Li, Wang Dongbo, Jun Shan. Macroinvertebrate community structure and relationships with environmental factors in the Lhasa River Basin. Acta Ecologica Sinica, 2019, 39 (3): $757 \sim 769$

21. Lu Huiting, Huang Qiongzhong, Zhu Jieyuan, et. al. Ecosystem type and quality changes in Lhasa River Basin and their effects on ecosystem services Acta Ecologica Sinica, 2018, 38 (24): $8911 \sim 8918$

22. Chen Xiaojing. Study on Watershed Management Law: From the Perspective of Ecosystem Management [D]. Ocean University of China, 2006.

23. Chen Xiaojing. Study on Watershed Management Law: From the Perspective of Ecosystem Management [D]. Ocean University of China, 2006.

24. Chen Kun, Jin Tiantian, Su Huidong, et al. Construction and application of river health assessment index system in Lhasa River [J]. Acta Ecologica Sinica, 2019, 39 (3).

25. Jia Yangwen. Principles and Practices of Distributed Watershed Hydrological Models [M]. China Water Resources and Hydropower Press, 2005.

26. Fildes R. Forecasting, Structural Time Series Models and the Kalman Filter, by Andrew C. Harvey; Bayesian Forecasting and Dynamic Models, by Mike West; Jeff Harrison[M]// Forecasting, structural time series models and the Kalman filter /. Cambridge University Press, 1990:1031-1033. 